\title{
Calculation of energy deposited and stopping range through deuterium ignition beam and dynamical studies on the energy gain in $\mathrm{D}-{ }^{3} \mathrm{He}$ mixtures
}

\author{
S. N. Hosseinimotlagh ${ }^{* 1}$, M.Jahedi ${ }^{2}$, S.Kianafraz ${ }^{3}$,S.Ghaderi ${ }^{4}$
}

Accepted $15^{\text {th }}$ August 2014

\begin{abstract}
The fast ignition approach to ICF consists in first compressing the fuel to high density by a suitable driver and then creating the hot spot required for ignition by means of a second external pulse. If the ignition beam is composed of deuterons, an additional energy is delivered to the target with increased energy gain. Therefore, in this innovative suggestion, we consider deuterium beams for fast ignition in $\mathrm{D}+{ }^{3} \mathrm{He}$ mixture and solve the dynamical balance equations under the available physical conditions by considering a new average reactivity formula ,then we compute the energy gain in this mixture .Our computational results show that we can get energy gain value larger than 1000 at resonant temperature $(380 \mathrm{keV})$ of $\mathrm{D}+{ }^{3} \mathrm{He}$ mixture. We select $\mathrm{D}+{ }^{3} \mathrm{He}$ fuel, because $\mathrm{D}+{ }^{3} \mathrm{He}$ reaction is very attractive from a theoretical point of view since it does not produced neutrons. The $\mathrm{D}+{ }^{3} \mathrm{He}$ benefits include full-lifetime materials, reduced radiation damage, less activation, absence of tritium breeding blankets, highly efficient direct energy conversion, easier maintenance, proliferation resistance. The deposited energy can reduce laser driver energy. Our calculations show that at $380 \mathrm{Kev}$ (resonant temperature) the maximum numbers of fusion reactions are performed and the energy gain is maximized.
\end{abstract}

Keywords: Fast Ignition, Deuteron Beam, Energy, Dynamics.

\section{Introduction}

There is no doubt that one of the most difficult problems that a peaceful world will face in the 21th century will be to secure an adequate ,safe ,clean and economical source of energy. Fusion energy which is the energy source that powers the stars has its origin in nuclear fusion reactions. Inertial confined fusion (ICF) is the major alternative to magnetic confined fusion. The indirect and direct drive approaches to ICF have been reviewed respectively by Lindl et al. (1995 and 2004) [1] and Bodner (1998)[2]. Both rely on implosion of a spherical shell of deuterium -tritium ice with a central core of $\mathrm{D}+\mathrm{T}$ gas to compress and ignite the fuel at a central hot spot. Fast ignition (FI) is a newer approach to ICF proposed in outline by Basov et al (1992)[3] and in much fuller detail by Tabak et al. (1994)[4]. Fuel compression and ignition are separated in FI by using a shell of fuel at solid density which is compressed by long pulse beams, together with short duration localized heating and ignition of the compressed fuel by a short pulse laser . The original concept of Tabak et al. assumed that short pulse laser beam would penetrate close to the dense fuel through a laser formed channel in the plasma and that laser generated relativistic electrons would ignite the fuel. Over the past year, there have been several observations of multi- $\mathrm{MeV}$ ion beams generated by high-intensity ultrashort laser pulses in the interaction with solid targets [5]. Light ions, similar to electrons, can be generated due to laser-plasma interaction in a target, while a heavy ion beam must be produced by an external driver and transported to the target. In summary, the fast ignition (FI) mechanism [4], in which a pellet containing the thermonuclear fuel is first compressed by a nanosecond laser pulse, and then irradiated by an intense "ignition"

\footnotetext{
${ }^{1-4}$ Department of Physics, Shiraz Branch, Islamic Azad University, Shiraz, Iran

* Corresponding Author Email: hoseinimotlagh@ hotmail.com

Note: This paper has been presented at the International Conference on Advanced Technology\&Sciences (ICAT'14) held in Antalya (Turkey), August 12-15, 2014.
}

beam, initiated by a high power picosecond laser pulse, is one of the promising approaches to the There is no doubt that one of the most difficult problems that a peaceful world will face in the 21 th century will be to secure an adequate, safe, clean and economical source of energy. Fusion energy which is the energy source that powers the stars has its origin in nuclear fusion reactions. Inertial confined fusion (ICF) is the major alternative to magnetic confined fusion. The indirect and direct drive approaches to ICF have been reviewed respectively by Lindl et al. (1995 and 2004) [1] and Bodner (1998)[2]. Both rely on implosion of a spherical shell of deuterium -tritium ice with a central core of $\mathrm{D}+\mathrm{T}$ gas to compress and ignite the fuel at a central hot spot. Fast ignition (FI) is a newer approach to ICF proposed in outline by Basov et al (1992)[3] and in much fuller detail by Tabak et al. (1994)[4]. Fuel compression and ignition are separated in FI by using a shell of fuel at solid density which is compressed by long pulse beams, together with short duration localized heating and ignition of the compressed fuel by a short pulse laser. The original concept of Tabak et al. assumed that short pulse laser beam would penetrate close to the dense fuel through a laser formed channel in the plasma and that laser generated relativistic electrons would ignite the fuel. Over the past year, there have been several observations of multi-MeV ion beams generated by high-intensity ultrashort laser pulses in the interaction with solid targets [5]. Light ions, similar to electrons, can be generated due to laser-plasma interaction in a target, while a heavy ion beam must be produced by an external driver and transported to the target. In summary, the fast ignition (FI) mechanism [4], in which a pellet containing the thermonuclear fuel is first compressed by a nanosecond laser pulse, and then irradiated by an intense "ignition" beam, initiated by a high power picosecond laser pulse, is one of the promising approaches to the realization of the inertial confinement fusion (ICF). The ignition beam could consist of laser-accelerated electrons, protons, heavier ions, or could consist of the laser beam itself. It had been predicted that the FI mechanism would require much smaller overall laser energies to achieve ignition than the 
more conventional central hot spot approach, and that it could deliver a much higher fusion gain, due to peculiarities of the pressure and density distributions during the ignition. If the ignition beam is composed of deuterons, an additional energy is delivered to the target and increase target energy gain. Therefore, in this work we choose the $\mathrm{D}+{ }^{3} \mathrm{He}$ fuel with a deuteron ignition beam, under optimum conditions for the first time we compute the total energy deposited in the target and dynamically we determine energy gain. We must notice that $\mathrm{D}+{ }^{3} \mathrm{He}$ has different advantages: they include full-lifetime materials, reduced radiation damage, less activation, absence of tritium breeding blankets, highly efficient direct energy conversion, easier maintenance, proliferation resistance.

\section{Physics of Fusion Reactions}

The main fusion reactions are:

$\mathrm{D}+\mathrm{T} \rightarrow{ }_{2}^{4} \mathrm{He}(3.5 \mathrm{MeV})+n(14.1 \mathrm{MeV})$

$D+{ }_{2}^{3} \mathrm{He} \rightarrow{ }_{2}^{4} \mathrm{He}(3.6 \mathrm{MeV})+p(14.7 \mathrm{MeV})$

$D+D \rightarrow{ }_{2}^{3} \mathrm{He}(0.82 \mathrm{MeV})+n(2.45 \mathrm{MeV})$ since it does not produced neutrons. A D+ ${ }^{3} \mathrm{He}$ fuelled fusion reactor would also possess substantial safety and environmental advantages over D+T. Efficient $\mathrm{D}+{ }^{3} \mathrm{He}$ fusion energy would be beneficial to terrestrial electricity, space power, and space propulsion. Fusion using $\mathrm{D}+{ }^{3} \mathrm{He}$ fuel requires significant physics development particularly of plasma confinement in high performance alternate fusion concept. Economically accessible ${ }^{3} \mathrm{He}$ on earth exists in sufficient quantities (a few hundred $\mathrm{kg}$, equivalent to few thousand $\mathrm{MW}$-years of fusion power) for an engineering test. In a $\mathrm{D}+\mathrm{T}$ and $\mathrm{D}+{ }^{3} \mathrm{He}$ fuel mixture $\mathrm{D}+\mathrm{D}$ reaction fusion also occurs. The main difficulties for $\mathrm{D}+3 \mathrm{He}$ reaction are the high temperature conditions and the scarceness of $3 \mathrm{He}$ on earth. The formula of fusion cross section for all these fusion reactions is given by: [6]

$$
\begin{aligned}
\sigma\left(E_{\text {lab }}\right)=-16389 C_{3}( & \left.+\frac{m_{a}}{m_{b}}\right)^{2} \\
& \times\left[m _ { a } E _ { \text { lab } } \left[\operatorname{Exp}\left(31.40 Z_{1} Z_{2} \sqrt{\frac{m_{a}}{E_{\text {lab }}}}\right)\right.\right. \\
& -1]\left\{\left(C_{1}+C_{2} E_{\text {lab }}\right)^{2}\right. \\
& \left.\left.+\left(C_{3}-\frac{2 \pi}{\left[\operatorname{Exp}\left(31.40 Z_{1} Z_{2} \sqrt{m_{a} / E_{\text {lab }}}\right)-1\right]}\right)^{2}\right\}\right]^{-1}
\end{aligned}
$$

With 3 adjustable parameters $\left(C_{1}, C_{2}\right.$ and $\left.C_{3}\right)$ only. In equation (1), $m_{a}$ and $m_{b}$ are the mass number for the incident and target nucleus, respectively (e.g. $\quad m_{a}=2$ for incident deuteron); $E_{l a b}$ (deuteron energy in lab system) is in units of Kev and $\sigma$ is in units of barn. The numerical values of $C_{1}, C_{2}$ and $C_{3}$ are given inRef.10.From this formula, we calculated and plotted the variations of fusion cross sections for these reactions in terms of $E_{\text {lab }}$. Also by comparing our calculated numerical values with available experimental results as are shown in [9], we concluded that this formula is very exact. Another important quantity is the reactivity, defined as the probability of reaction per unit time per unit density of target nuclei. In the present simple case, it is just given by the product $\langle\sigma v\rangle$. In general, target nuclei move, so that the relative velocity $\mathrm{v}$ is different for each pair of interacting nuclei. In this case, we compute an averaged reactivity $\langle\sigma v\rangle=$ $\int_{0}^{\infty} \sigma(v) v f(v) d v$ where $f(v)$ is the distribution functioning of the relative velocities, normalized in such a way that $\int_{0}^{\infty} f(v) d v=1$. As we have seen earlier, the effectiveness of a fusion fuel is characterized by its reactivity $\langle\sigma v\rangle$. Both in controlled fusion and in astrophysics we usually deal with mixtures of nuclei of different species, in thermal equilibrium, characterized by Maxwellian velocity distributions $f_{j}\left(v_{j}\right)=$ $\left(\frac{m_{j}}{2 \pi k_{B} T}\right)^{\frac{3}{2}} \exp \left(-\frac{m_{j} v_{j}^{2}}{2 k_{B} T}\right)$ where the subscript $\mathrm{j}$ labels the species, $\mathrm{T}$ is the temperature and $k_{B}$ is Boltzmann constant. The expression for the average reactivity $\langle\sigma v\rangle$ can now be written as: $\langle\sigma v\rangle$ $=\iint d v_{1} d v_{2} \sigma_{1,2}(v) v f_{1}\left(v_{1}\right)$ where $\mathrm{v}=\left|\mathrm{v}_{1}-\mathrm{v}_{2}\right|$ and the integrals are taken over the three-dimensional velocity space. In order to put $<\sigma \mathrm{v}\rangle$ in a form suitable for integration, we express the velocities $v_{1}$ and $v_{2}$ by means of the relative velocity and of the center-ofmass velocity $v_{c}=\frac{m_{1} v_{1}+m_{2} v_{2}}{m_{1}+m_{2}}: v_{1}=v_{c}+\frac{v_{2}}{m_{1}+m_{2}} a{ }^{2} v_{2}=$ $\mathrm{v}_{\mathrm{c}^{-}} \frac{\mathrm{vm}_{1}}{\mathrm{~m}_{1}+\mathrm{m}_{2}}$ then becomes:

$<\sigma \mathrm{v}>=$

$\frac{\left(m_{1} m_{2}\right)^{\frac{3}{2}}}{\left(2 \pi k_{B} T\right)^{3}} \iint d v_{1} d v_{2} \exp \left(-\frac{\left(m_{1}+m_{2}\right) v_{c}^{2}}{2 \pi k_{B} T}-\frac{m_{r} v^{2}}{2 k_{B} T}\right) \sigma(v) v$

Where $m_{r}$ is the reduced mass defined bym $\mathrm{m}_{\mathrm{r}}=\frac{\mathrm{m}_{1} \mathrm{~m}_{2}}{\mathrm{~m}_{1}+\mathrm{m}_{2}}$, and the subscripts ' 1,2 ' have been omitted. It can be shown that the integral over $d v_{1} d v_{2}$ can be replaced by an integral overdv $d v$, so that we can write:

$$
\begin{aligned}
& <\sigma v> \\
& =\left[\left(\frac{m_{1}+m_{2}}{2 \pi k_{B} T}\right)^{\frac{3}{2}} \int d v_{c} \exp \left(-\frac{\left(m_{1}+m_{2}\right) v_{c}^{2}}{2 \pi k_{B} T}\right)\right. \\
& \left.\times\left(\frac{m_{r} v^{2}}{2 k_{B} T}\right)^{\frac{3}{2}} \int d v \exp \left(-\frac{m_{r} v^{2}}{2 k_{B} T}\right) \sigma(v) v\right]
\end{aligned}
$$

The term in square brackets is unity, being the integral of a normalized Maxwellian, and we are left with the integral over the relative velocity. By writing the volume element in velocity space as $\mathrm{dV}=4 \pi \mathrm{v}^{2} \mathrm{dv}$, and using the definition $\varepsilon=\frac{1}{2} \mathrm{~m}_{\mathrm{r}} \mathrm{v}^{2}$ of center-of-mass energy $\varepsilon$, we finally get: $\langle\sigma \mathrm{V}\rangle=$ $\frac{4 \pi}{\left(2 \pi \mathrm{m}_{\mathrm{r}}\right)^{\frac{1}{2}}} \frac{1}{\left(\mathrm{k}_{\mathrm{B}} \mathrm{T}\right)^{\frac{3}{2}}} \int_{0}^{\infty} \sigma(\varepsilon) \varepsilon \exp \left(-\frac{\varepsilon}{\mathrm{k}_{\mathrm{B}} \mathrm{T}}\right) \mathrm{d} \varepsilon$ We must notice that the resonance temperature, where we have maximum probability for occurring fusion. From Figure 1 we see clearly that resonant temperature for both $\mathrm{D}+{ }^{3} \mathrm{He}$ and $\mathrm{D}+\mathrm{D}$ fusion reactions are approximately 100 and $380 \mathrm{keV}$, respectively.

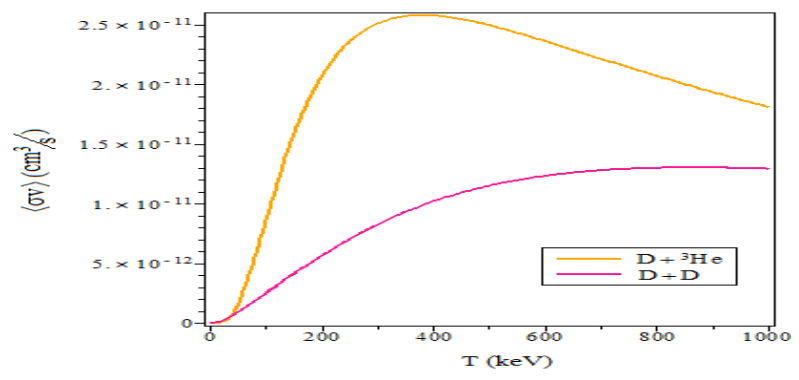

Fig 1:Variations of the averaged reactivity in terms of temperature for $<\sigma \mathrm{V}>_{\mathrm{D}+{ }^{3} \mathrm{He}}$ and $<\sigma \mathrm{V}>_{D+D}$

\section{Total deposited energy due to deuteron beam fast ignition in target fuel}

Deuterons have been considered for fast ignition as well. Bychenkov et al., considered an accelerated deuteron beam, but decided that deuterons would have too high an energy (7-8 MeV) to form the desired hot spot [7] .However, the recent proton acceleration experiments [8] suggest that the laser and converter foil parameters can be adjusted to achieve ion beams within the desired range of initial energies and spectra with low $\frac{\Delta E}{E}$ for maximum use of the beam. This reopens the door to a 
consideration of deuteron driven FI. Deuterons would not only provide proven ballistic focusing, but also fuse with the target fuel (both $\mathrm{D}$ and ${ }^{3} \mathrm{He}$ ) as they slow down [9] , providing a "bonus" energy gain. Depending on the target plasma conditions, this added fusion gain can provide a significant contribution. We must notice that idea of bonus energy for first time is presented by Xiaoling Yang and et.al at low temperatures. In this work we elaborate on this idea, to compute the added energy released as the energetic deuterons interact with the target fuel ions of $\mathrm{D}+{ }^{3} \mathrm{He}$ in range of temperatures including resonant ones $(380 \mathrm{keV})$. This added energy increases the total energy gain.We use a modified energy multiplication factor $\varphi$ to estimate the bonus energy in terms of the added "hot spot" heating by beam-target fusion reaction for $\mathrm{D}+{ }^{3} \mathrm{He}$ [9]. The deuteron beam energy deposition range and time are also calculated for this reaction. The $\mathrm{F}$ value is the ratio between the fusion energy $E_{\mathrm{f}}$ produced and the ion energy input $E_{I}$ to the plasma and for $\mathrm{D}+{ }^{3} \mathrm{He}$ reaction is given by [9] : $\mathrm{F}_{\mathrm{D}+{ }^{3} \mathrm{He}}=$ $\mathrm{n}^{3} \mathrm{He} \frac{\int_{\mathrm{E}_{\mathrm{th}}}^{\mathrm{E}_{\mathrm{I}}} \mathrm{S}(\mathrm{E}) \mathrm{dE}}{\mathrm{E}_{\mathrm{I}}}$ where $\mathrm{E}_{\mathrm{I}}$ and $\mathrm{E}_{\text {th }}$ are, respectively, the average initial energy and the asymptotic thermalized energy of the injected single ion for this reactions.[18,21,22].So, we consider $\mathrm{S}(\mathrm{E}) \equiv$ $\sum_{\mathrm{k}} \mathrm{K}_{\mathrm{k}}\left[<\sigma \mathrm{v}(\mathrm{E})>_{\mathrm{b}}\right]_{\mathrm{Ik}}\left(\mathrm{E}_{\mathrm{f}}\right)_{\mathrm{Ik}} /\left(\frac{\mathrm{dE}}{\mathrm{dt}}\right)$ where:

$\frac{1}{\mathrm{n}_{{ }_{\mathrm{He}} \mathrm{H}}}\left(\frac{\mathrm{dE}}{\mathrm{dt}}\right)=-\frac{\mathrm{Z}_{\mathrm{I}}^{2} \mathrm{e}^{4} \mathrm{~m}_{\mathrm{e}}^{1 / 2} \mathrm{E} \ln \Lambda_{\mathrm{D}+}{ }^{3} \mathrm{He}}{3 \pi(2 \pi)^{1 / 2} \varepsilon_{0}^{2} \mathrm{~m}_{\mathrm{I}}\left(\mathrm{kT}_{\mathrm{e}}\right)^{3 / 2}}\left[1+\frac{3 \sqrt{\pi} \mathrm{m}_{\mathrm{I}}^{3 / 2}\left(\mathrm{kT} \mathrm{e}^{3 / 2}\right.}{4 \mathrm{~m}_{\mathrm{k}} \mathrm{m}_{\mathrm{e}}^{1 / 2} \mathrm{E}^{3 / 2}}\right]$

where $m_{e}$ is the mass of electron and $m_{l}$ is the mass of the injected ion, both of which are in atomic mass unit (amu). $\langle\sigma \mathrm{V}\rangle_{\mathrm{Ik}}$ is the fusion reactivity for the injected ion $I$ of species $k$ having atomic fraction $K_{k}$ in the target, $\left(E_{f}\right)_{I k}$ is the corresponding energy released per fusion, and $\mathrm{T}_{\mathrm{e}}$ is the target electron temperature. By inserting Eq. (3) inside $\mathrm{F}_{\mathrm{D}+{ }^{3} \mathrm{He}}$ ) we can see that the $\mathrm{n}^{3} \mathrm{He}$ in Eq (4) cancel that in $\mathrm{F}_{\mathrm{D}+{ }^{3} \mathrm{He}}$, thus $\mathrm{F}_{\mathrm{D}+{ }^{3} \mathrm{He}}$ is nearly independent of the target density $\left(\left(\mathrm{n}^{3} \mathrm{He}\right) \cdot \ln \Lambda_{\mathrm{D}+{ }^{3} \mathrm{He}}\right.$ is the Coulomb logarithm for $\mathrm{D}+{ }^{3} \mathrm{He}$ reaction. In the $\mathrm{D}+{ }^{3} \mathrm{He}$ fusion reaction the products are all energetic charged particles (14.7 MeV proton and $3.6 \mathrm{MeV}$ alpha ) based on the binary collision model, the Coulomb logarithm based slowing down process in the back ground plasma is usually defined as: $\ln \Lambda_{\mathrm{D}+}{ }^{3} \mathrm{He}=14.8-\ln \left(\sqrt{\mathrm{n}_{\mathrm{e}}} / \mathrm{T}_{\mathrm{e}}\right)$. The $\left(\mathrm{E}_{\mathrm{f}}\right)_{\mathrm{Ik}}$ in $\mathrm{S}(\mathrm{E})$ gives the energy released in the fusion reaction carried by the produced particles. For, $\mathrm{D}+{ }^{3} \mathrm{He}$ reaction in the target (see reaction (b)) only $20 \%$ of the fusion energy carried by the alphas is useful for heating while for the $\mathrm{D}+\mathrm{D}$ reaction about $63 \%$ of the total is applicable (see reaction $\mathrm{c}$ ). Therefore, to prevent confusion, we introduce a new factor $\varphi$ to represent the energy multiplication factor for the hot spot heating by the charged particles for $\mathrm{D}+{ }^{3} \mathrm{He}$ fusion reaction. We have $\varphi_{\mathrm{D}+{ }^{3} \mathrm{He}}=20 \% \mathrm{~F}_{\mathrm{D}+{ }^{3} \mathrm{He}}$ and for $\mathrm{D}+\mathrm{D}$ fusion in $\mathrm{D}+{ }^{3} \mathrm{He}$ mixture $\varphi_{\mathrm{D}+\mathrm{D}}=63 \% \mathrm{~F}_{\mathrm{D}+{ }^{3} \mathrm{He}}$. In summary, the total energy that could be deposited into the target due to combined deuteron ion heating and beam-target fusion for $\mathrm{D}+{ }^{3} \mathrm{He}$ and $\mathrm{D}+\mathrm{D}$ respectively becomes: $\varepsilon_{\mathrm{D}+}{ }^{3} \mathrm{He}=\mathrm{E}_{\mathrm{I}}\left(1+\varphi_{\mathrm{D}+{ }^{3} \mathrm{He}}\right)$ and $\varepsilon_{\mathrm{D}+\mathrm{D}}=\mathrm{E}_{\mathrm{I}}\left(1+\varphi_{\mathrm{D}+\mathrm{D}}\right)$ so it is seen that $\varphi$ plays the role of a "bonus energy" for deuteron driven fast ignition. To avoid confusion, please note that the $\varepsilon$ here is the total energy deposited by the ion beam plus any contribution from its beam-target fusion in the hot spot, but not the total input energy to the target which is often cited in energy studies and represents the total laser compression plus fast ignition energy delivered to the total target ,also the deuteron stopping range and stopping time can be calculated by following equations [9]: $\mathrm{R}_{\mathrm{S}}=\int_{\mathrm{E}_{\mathrm{th}}}^{\mathrm{E}_{\mathrm{I}}} \mathrm{v}_{\mathrm{D}} \mathrm{dE} /\left(\frac{\mathrm{dE}}{\mathrm{dt}}\right)$ and $\mathrm{t}_{\mathrm{S}}=\int_{\mathrm{E}_{\mathrm{th}}}^{\mathrm{E}_{\mathrm{I}}} \mathrm{dE} /\left(\frac{\mathrm{dE}}{\mathrm{dt}}\right)$ Where, $\left(\frac{d E}{d t}\right)$ are calculated from Eq.(3) for
$\mathrm{D}+{ }^{3} \mathrm{He}$ reactions ,the deuteron velocity is $\mathrm{v}_{\mathrm{D}}=\sqrt{\frac{2 \mathrm{E}}{\mathrm{m}_{\mathrm{D}}}}$. For calculating the total energy deposited into the target of $\mathrm{D}+{ }^{3} \mathrm{He}$ mixture at first step we substitute $: \ln A_{\mathrm{D}+} \mathrm{a}_{\mathrm{m} z}$ into equation (3), then at second step the obtained result is replaced into $S(E)$ and at third step the result of second step is inserted into $\mathrm{F}_{\mathrm{D}+{ }^{3} \mathrm{He}}$ and we compute, $\mathrm{F}_{\mathrm{D}+{ }^{3} \mathrm{He}}$ and $\mathrm{F}_{\mathrm{D}+\mathrm{D}}$ in $\mathrm{D}+{ }^{3} \mathrm{He}$ reaction at step 4 we use these parameters for determining $\varphi_{\mathrm{D}+\mathrm{D}}$ and $\varphi_{\mathrm{D}+}{ }^{3} \mathrm{He}$ Finally, results are delivered by the last step inserted in $\sigma\left(E_{\mathbb{l a b}}\right)$ and thus we have the numerical values of $\varepsilon_{\mathrm{D}+}{ }^{3} \mathrm{He}, \varepsilon_{\mathrm{D}+\mathrm{D}}$ in $\mathrm{D}+{ }^{3} \mathrm{He}$ for $10^{26} \leq \mathrm{n}_{\mathrm{e}}\left(\mathrm{cm}^{-3}\right) \leq 10^{29}, 0 \leq \mathrm{T}_{\mathrm{e}}(\mathrm{keV}) \leq 380$ and deuteron energy $\mathrm{E}$, with range of $0 \leq \mathrm{E}(\mathrm{MeV}) \leq 10$. (see Table1) Also under these conditions we can calculate the deuteron stopping range and stopping time using equations $R_{S}$ and $t_{s}$. For $\mathrm{D}+{ }^{3} \mathrm{He}$ mixture these parameters are shown respectively, by $\mathrm{t}_{\mathrm{S}_{\mathrm{D}+}{ }^{3} \mathrm{He}}, \mathrm{R}_{\mathrm{S}_{\mathrm{D}+{ }^{3} \mathrm{He}}}$. The numerical results about above discussion are given in Figs. 2 to 4. Our calculations show that multiplication factors $\varphi_{\mathrm{D}+\mathrm{D}}, \varphi_{\mathrm{D}+{ }^{3} \mathrm{He}}$ increases by increasing temperature from 1 to $380 \mathrm{keV}$ (resonance temperature of $\mathrm{D}+{ }^{3} \mathrm{He}$ ) and also by increasing energy from 0 to $10000 \mathrm{keV}$ increases slowly till at the deuteron energy in lab system maximized and after this energy slowly decreases. The value of total energy deposited in hot spot $\left(\varepsilon_{\mathrm{D}+}{ }^{3} \mathrm{He}\right.$ and $\left.\varepsilon_{\mathrm{D}+\mathrm{D}}\right)$ by increasing temperature from 1 to $380 \mathrm{keV}$ increases such that these total energy deposited at temperature 380 $\mathrm{KeV}$ respect to lower temperatures highly increases. Also, total energy deposited by increasing deuteron energy in range of 0 to $10000 \mathrm{keV}$ for low temperatures (about approximately $10 \mathrm{keV}$ ) increase approximately linearly. Also by increasing electron density from $\mathrm{n}_{\mathrm{e}}=10^{26}$ to $10^{29}\left(\mathrm{~cm}^{-3}\right)$ the amount of total deposited energy of $\varepsilon_{\mathrm{D}+}{ }^{3} \mathrm{He}$ and $\varepsilon_{\mathrm{D}+{ }^{3} \mathrm{He}}$ and also the amount of multiplication factors $\varphi_{\mathrm{D}+}{ }^{3} \mathrm{He}$ and $\varphi_{\mathrm{D}+\mathrm{D}_{\mathrm{a}}}$ are decreased. From comparing numerical values of multiplication factors $\varphi_{\mathrm{D}+\mathrm{D}_{\mathrm{a}}}$ and $\varphi_{\mathrm{D}+}{ }^{3} \mathrm{He}$ we can say that $\varphi_{\mathrm{D}+\mathrm{D}_{\mathrm{a}}}$ is very higher than $\varphi_{\mathrm{D}+{ }^{3} \mathrm{He}}$ .Therefore the total energy deposited $\varepsilon_{\mathrm{D}+\mathrm{D}_{\mathrm{a}}}$ is higher than $\varepsilon_{\mathrm{D}+{ }^{3} \mathrm{He}}$

The difference between them is more sensitive at high temperature (see TABLE.1). Also, our results clearly show that the stopping time remarkable increases by increasing temperature from $1 \mathrm{keV}$ to $380 \mathrm{keV}$, also $\mathrm{t}_{\mathrm{S}_{\mathrm{D}+}{ }^{3} \mathrm{He}}$ increases by increasing deuteron energy. We must notice that the values of $t_{S_{D+}{ }^{3} \mathrm{He}}$ is reduced by increasing electron density, $\mathrm{n}_{\mathrm{e}}$, from $10^{26}$ to $10^{29}\left(\mathrm{~cm}^{-3}\right)$.In these three dimensional figures is obvious the dependency of $t_{\mathrm{S}_{\mathrm{D}+}{ }^{3} \mathrm{He}}$ to temperature. Numerical results of $\mathrm{t}_{\mathrm{S}_{\mathrm{D}+}{ }^{3} \mathrm{He}}$ show that stopping time is increased by increasing temperature. The effect of helium-3 density ( $\mathbf{n}^{3} \mathrm{He}$ ) from $10^{22}$ to $10^{24}\left(\mathrm{~cm}^{-3}\right)$ is important on the value of $\mathrm{t}_{\mathrm{D}+{ }^{3} \mathrm{He}}$ and in this range this quantity is reduced (by factor $\mathrm{O}(10)$ to $\mathrm{O}(100)$ ). Our calculations show that show that stopping range $\left(\mathrm{R}_{\mathrm{S}+{ }^{3} \mathrm{He}}\right)$ is increased strongly by increasing temperature from $1 \mathrm{keV}$ to $380 \mathrm{keV}$ and also deuteron energy in lab system is an effective parameter on the stopping power such that by increasing this energy $\mathrm{R}_{\mathrm{S}_{\mathrm{D}+}{ }^{3} \mathrm{He}}$ is increased. But the numerical values of $\mathrm{R}_{\mathrm{S}_{\mathrm{D}+}{ }^{3} \mathrm{He}}$ are decreased by increasing electron density $\mathbf{n}_{\mathbf{e}}$ from $10^{26}$ to $10^{29}\left(\mathrm{~cm}^{-3}\right)$. The other parameter that effects on the numerical values of $\mathrm{R}_{\mathrm{S}_{\mathrm{D}+}{ }^{3} \mathrm{He}}$ is target density $(\rho)$. If $\rho$ changes from 200 to $500 \mathrm{~cm}^{-3}$, stopping range is increased. Also ,the other effective parameter that decreased stopping range, is $\mathrm{n}^{3} \mathrm{He}$. Our calculation shows that by changing $\mathrm{n}^{3} \mathrm{He}$ from $10^{22}$ to $10^{29}\left(\mathrm{~cm}^{-3}\right), \mathrm{R}_{\mathrm{S}_{\mathrm{D}+}{ }^{3} \mathrm{He}}$ is decreased by the order of 10 and 100 . 


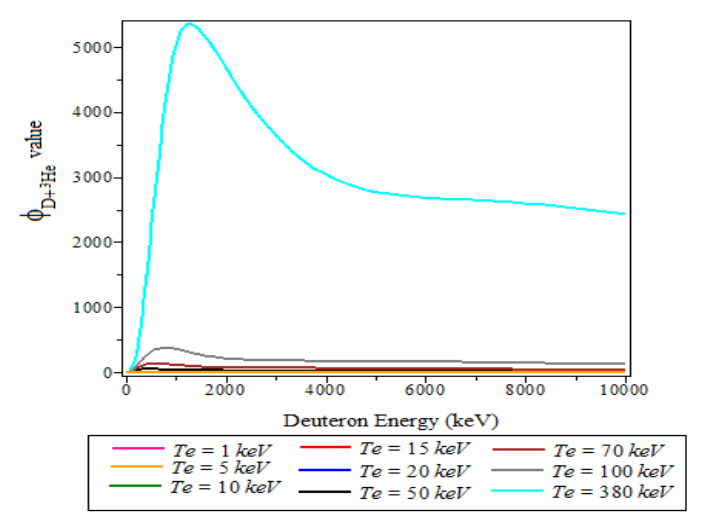

a)

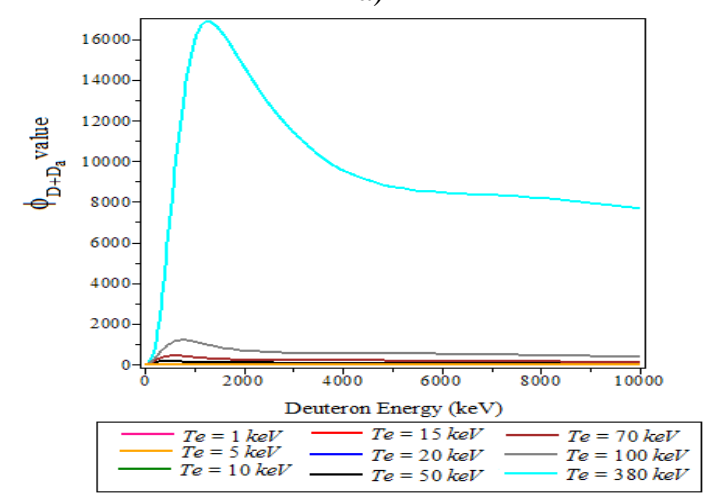

b)
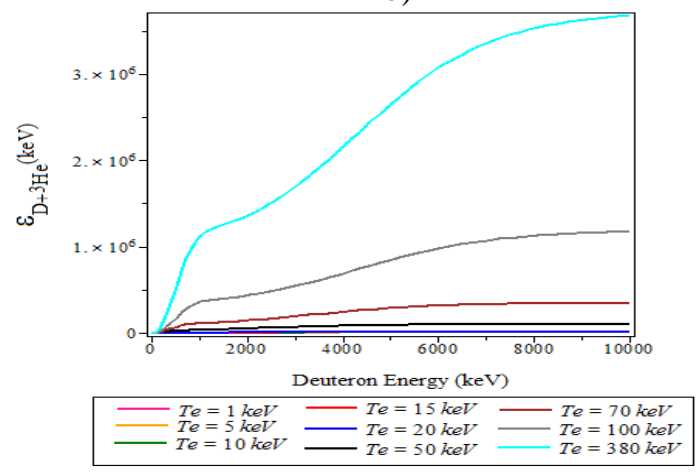

c)

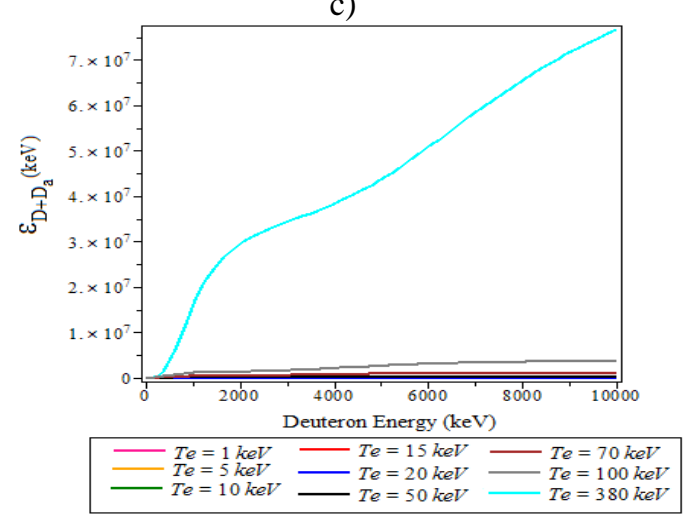

d)

Fig 2: The two dimensional variation of a) $\varphi_{\mathrm{D}+{ }^{3} \mathrm{He}}$ b) $\varphi_{\mathrm{D}+\mathrm{D}_{\mathrm{a}}}$ c) $\varepsilon_{\mathrm{D}+{ }^{3} \mathrm{He}} \quad$ d) $\varepsilon_{\mathrm{D}+\mathrm{D}_{\mathrm{a}}}$ in terms of deuteron energy in different temperature in $\mathrm{D}+{ }^{3} \mathrm{He}$ mixture for $\mathrm{n}_{\mathrm{e}}=10^{26} \mathrm{~cm}^{-3}$.

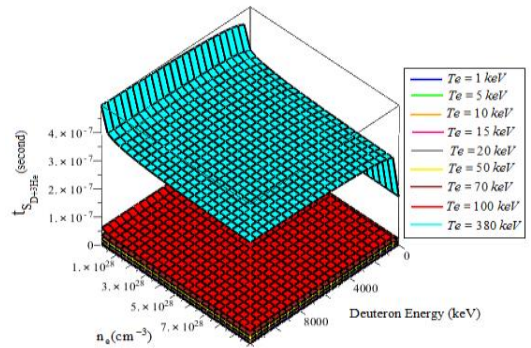

Fig 3: Three dimensional variations of stopping time versus electron density and deuteron energy in different temperatures in different density of ${ }^{3} \mathrm{He} \quad \mathrm{n}_{3 \mathrm{He}}=10^{22}\left(\mathrm{~cm}^{-3}\right)$.

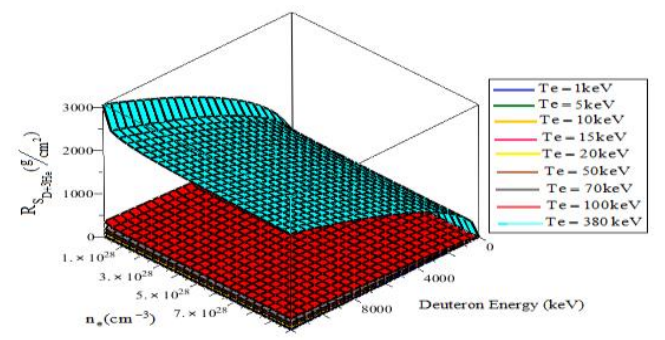

Fig 4: The three dimensional variations of stopping range versus electron density and deuteron energy in different temperatures in D+ ${ }^{3} \mathrm{He}$ mixture.at $\rho=300\left(\mathrm{~g} / \mathrm{cm}^{3}\right)$ and $\mathrm{n}_{{ }_{3} \mathrm{He}}=10^{23}\left(\mathrm{~cm}^{-3}\right)$

\section{Balance equations of deuterium-helium3 mixture}

The following system of equations is used to describe the temporal evolution of plasma parameters averaged over the volume (the density of deuterium ions $\mathrm{n}_{\mathrm{D}}$, density of hellium- 3 ions $\mathrm{n}^{3} \mathrm{He}$, density of thermal alpha-particlesn $\alpha$, plasma energy $E$ ), for $\mathrm{D}+{ }^{3} \mathrm{He}$ nuclear fusion reaction :

$\frac{d n_{D}}{d t}=-\frac{n_{D}}{\tau_{P}}-n_{D} n^{3}{ }_{H e}\langle\sigma v\rangle_{D+{ }^{3} H e}+S_{D}$

$\frac{d n^{3} \mathrm{He}}{d t}=-\frac{n_{{ }^{3} \mathrm{He}}}{\tau_{P}}-n_{D} n{ }_{{ }^{3} \mathrm{He}}\langle\sigma v\rangle_{D+{ }^{3} \mathrm{He}}+S_{{ }^{3} \mathrm{He}}$

$\frac{d n_{\alpha}}{d t}=-\frac{n_{\alpha}}{\tau_{\alpha}}+n_{D} n^{3} \mathrm{He}\langle\sigma v\rangle_{D+{ }^{3} \mathrm{He}}$

The energy balance is given by

$$
\frac{d E}{d t}=-\frac{E}{\tau_{E}}+Q_{\alpha} n_{D} n{ }^{3} \mathrm{He}\langle\sigma v\rangle_{D+{ }^{3} \mathrm{He}}-P_{\text {rad }}
$$

$S_{D}$, and $S_{{ }^{H} \mathrm{He}}$ are the source terms which give us the fuel rates; $\tau_{\alpha}, \tau_{P}$, and $\tau_{E}$ are the lifetimes of thermal alpha-particles, deuterium and hellium-3, and the energy confinement time, respectively, also the energy of the alpha particles is: $Q_{\alpha}=$ $3.52 \mathrm{MeV}=3.6 \times 10^{6} \times 1.6 \times 10^{-19} \mathrm{~J}$. The radiation loss $P_{\text {rad }}$ is given by: $\mathrm{P}_{\text {rad }}=\mathrm{P}_{\mathrm{brem}}=\mathrm{A}_{\mathrm{b}} \mathrm{Z}_{\mathrm{eff}} \mathrm{n}_{\mathrm{e}}^{2} \sqrt{\mathrm{T}}$ Where $\mathrm{A}_{\mathrm{b}}=5.35 \times$ $10^{-37} \frac{\mathrm{Wm}^{3}}{\sqrt{\mathrm{keV}}}$ is the bremsstrahlung radiation coefficient. No explicit evolution equation is provided for the electron density $n_{e}$ since we can obtain it from the neutrality condition $\mathrm{n}_{\mathrm{e}}=\mathrm{n}_{\mathrm{D}}+$ $\mathrm{n}^{3} \mathrm{He}+2 \mathrm{n}_{\alpha}$, whereas the effective atomic number, the total density and the energy are written as $\mathrm{Z}_{\text {eff }}=\frac{\sum_{\mathrm{i}} \mathrm{n}_{\mathrm{i}} \mathrm{Z}_{\mathrm{i}}^{2}}{\mathrm{n}_{\mathrm{e}}}=$ $\frac{\mathrm{n}_{\mathrm{D}}+\mathrm{n}_{{ }_{3 \mathrm{He}}+4 \mathrm{n}_{\alpha}}}{\mathrm{n}_{\mathrm{e}}}$ where, $Z_{i}$ is the atomic number of the different ions. The fusion energy gain is defined as: $G(t)=\frac{E_{f}(t)}{E_{\text {driver }}}$. Where $E_{f}(t)$ is equal to the energy due to the number of occurred fusion reactions in target in terms of time and $E_{\text {driver }}$ is the required energy for triggering fusion reactions in hot spot and is equal to $4 \mathrm{MJ}$. Also the fusion power density for $\mathrm{D}+{ }^{3} \mathrm{He}$ reaction is given 
by $\mathrm{P}_{\mathrm{D}+{ }^{3} \mathrm{He}}=\mathrm{n}_{\mathrm{D}}(\mathrm{t}) \mathrm{n}^{3} \mathrm{He}(\mathrm{t})<\sigma \mathrm{V}>_{\mathrm{D}+{ }^{3} \mathrm{He}} \mathrm{Q}_{\mathrm{D}+{ }^{3} \mathrm{He}}$

where $\mathrm{Q}_{\mathrm{D}+{ }^{3} \mathrm{He}}=18.3 \mathrm{MeV}$. We solve equations(4-1), (4-2, (43)and (4-4)( in dynamical state (time-dependent density of atoms) with the use of computers under available physical conditions .Our computational obtained results are given in TABLE.2. we see clearly that ,by increasing temperature from $1 \mathrm{keV}$ to $380 \mathrm{keV}$ the variations of deuterium and helium-3 density in terms of time $\left(\mathrm{n}_{\mathrm{D}}(\mathrm{t}), \mathrm{n}_{{ }^{3} \mathrm{He}}(\mathrm{t})\right)$ are decreased since that by increasing time the consumption rate of $n_{D}(t)$ and $n_{{ }^{3}} \mathrm{He}(t)$ are increased but the rate of this reduction at resonant temperature $380 \mathrm{keV}$ is more than respect to the other temperatures. Thus, by increasing temperature $1 \mathrm{keV}$ to $380 \mathrm{keV}$ the variations of alpha density $\left(\mathrm{n}_{\alpha}(\mathrm{t})\right)$ versus time at first by increasing time is increased and then decreased while the production rate of fusion plasma energy $\left(E_{\mathrm{f}}(\mathrm{t})\right)$ is increased until in resonant temperature $380 \mathrm{keV}$ is maximized because in this temperature the highest number of $\mathrm{D}+{ }^{3} \mathrm{He}$ fusion reaction is occurred. The numerical values of these quantities $\left(\mathrm{n}_{\alpha}(\mathrm{t})\right.$ andE $\left.\mathrm{E}_{\mathrm{f}}(\mathrm{t})\right)$ are decreased at temperature higher than $380 \mathrm{keV}$ since temperature $380 \mathrm{keV}$ is resonant temperature for $\mathrm{D}+{ }^{3} \mathrm{He}$ mixture. Also, our calculations show that by increasing the injection rate of deuterium and hellium-3 ( $\mathrm{S}_{\mathrm{D}}$ and $\left.\mathrm{S}_{{ }^{3} \mathrm{He}}\right)$ from $10^{22}$ to $10^{24} \mathrm{~cm}^{-3}$ the rate of variations of $\mathrm{n}_{\mathrm{D}}(\mathrm{t})$ and $\mathrm{n}^{3} \mathrm{He}(\mathrm{t})$ in terms of time are increased while for $\mathrm{n}_{\alpha}(\mathrm{t})$ and $\mathrm{E}_{\mathrm{f}}(\mathrm{t})$ are increased. We expect that in this temperature, energy gain and fusion power density are maximized .Therefore, for calculating these parameters we use of $S_{D}=S_{{ }^{3} \mathrm{He}}=10^{24} \mathrm{~cm}^{-3}$ (see TABLE3).

Table 1. Maximum numerical values of total energy deposited in $\mathrm{D}+{ }^{3} \mathrm{He}$ mixture at different temperature for $10^{26} \leq \mathrm{n}_{\mathrm{e}}\left(\mathrm{cm}^{-3}\right) \leq 10^{29}$.

\begin{tabular}{|l|l|l|l|}
\hline$n_{e}\left(\mathrm{~cm}^{-3}\right)$ & $\begin{array}{l}\mathrm{T}_{\mathrm{e}} \\
(\mathrm{keV})\end{array}$ & $\begin{array}{l}\varepsilon_{\mathrm{D}+}{ }^{3} \mathrm{He}_{\max } \\
(\mathrm{keV})\end{array}$ & \\
\hline $10^{26}$ & 15 & 10590.79627 & 11861.00824 \\
\hline $10^{26}$ & 50 & 101366.0808 & 297803.1545 \\
\hline $10^{26}$ & 100 & 1173268.091 & 3674294.486 \\
\hline $10^{26}$ & 380 & 3674294.486 & $7.673686266 \mathrm{E} 7$ \\
\hline $10^{27}$ & 15 & 10540.6978 & 11703.19806 \\
\hline $10^{27}$ & 50 & 92864.49313 & 271023.1533 \\
\hline $10^{27}$ & 100 & 1058602.594 & 3313098.17 \\
\hline $10^{27}$ & 380 & 3313098.17 & $6.819772378 \mathrm{E} 7$ \\
\hline $10^{28}$ & 15 & 10498.43168 & 11570.05979 \\
\hline $10^{28}$ & 50 & 85810.36076 & 248802.6364 \\
\hline $10^{28}$ & 100 & 964514.3416 & 3016720.176 \\
\hline $10^{28}$ & 380 & 3016720.176 & $6.136892405 \mathrm{E} 7$ \\
\hline $10^{29}$ & 15 & 10462.29433 & 11456.22713 \\
\hline $10^{29}$ & 50 & 79863.0243 & 230068.5265 \\
\hline $10^{29}$ & 100 & 885920.3924 & 2769149.236 \\
\hline $10^{29}$ & 380 & 2769149.236 & $5.578338395 \mathrm{E} 7$ \\
\hline
\end{tabular}

Table 2. Time dependent optimum numerical values of deuterium, helium-3, alpha particles densities and fusion plasma energy in different temperatures.

\begin{tabular}{|c|c|c|c|}
\hline $\begin{array}{c}\mathrm{T}_{\mathrm{e}} \\
(\mathrm{keV})\end{array}$ & $\begin{array}{c}\mathrm{T} \\
(\mathrm{s})\end{array}$ & $\begin{array}{l}P_{D+}{ }^{3} \mathrm{He} \\
\left(\frac{W}{\mathrm{Cm}^{3}}\right)\end{array}$ & $G_{D+{ }^{3} \mathrm{He}}(t)$ \\
\hline 15 & $10^{-20}$ & $491.94 \mathrm{E} 19$ & $5.72 \mathrm{E}-25$ \\
\hline 15 & $10^{-22}$ & $218.51 \mathrm{E} 15$ & $0.57248 \mathrm{E}-16$ \\
\hline 15 & 60 & $196.78 \mathrm{E}-4$ & $2.7776 \mathrm{E}-8$ \\
\hline 15 & 100 & $196.78 \mathrm{E}-4$ & $1.71496 \mathrm{E}-2$ \\
\hline 50 & $10^{-20}$ & $555.35 \mathrm{E} 21$ & $435.799 \mathrm{E}-22$ \\
\hline 50 & $10^{-22}$ & $391.77 \mathrm{E} 16$ & $2.378 \mathrm{E}-12$ \\
\hline 50 & 60 & $222.14 \mathrm{E}-2$ & $1.1536 \mathrm{E}-3$ \\
\hline 50 & 100 & $222.14 \mathrm{E}-2$ & $0.7124 \mathrm{E} 3$ \\
\hline 100 & $10^{-20}$ & $3144.01 \mathrm{E} 21$ & $2467.212 \mathrm{E}-22$ \\
\hline 100 & $10^{-22}$ & $4678.90 \mathrm{E} 13$ & $0.40904 \mathrm{E}-11$ \\
\hline 100 & 60 & $1257.60 \mathrm{E}-2$ & $1.98452 \mathrm{E}-3$ \\
\hline 100 & 100 & $943.20 \mathrm{E}-2$ & $1.22532 \mathrm{E} 3$ \\
\hline 380 & $10^{-20}$ & $954.43 \mathrm{E} 22$ & $7489.8807 \mathrm{E}-22$ \\
\hline 380 & $10^{-22}$ & $1195.97 \mathrm{E} 8$ & $0.44372 \mathrm{E}-11$ \\
\hline 380 & 60 & $381.77 \mathrm{E}-1$ & $2.15276 \mathrm{E}-3$ \\
\hline 380 & 100 & $381.77 \mathrm{E}-1$ & $1.3292 \mathrm{E} 3$ \\
\hline
\end{tabular}

Table 3. Time dependent numerical values of fusion power density and target energy gain at $\mathrm{S}_{\mathrm{D}}=0.63 \times 10^{24}\left(\mathrm{~cm}^{-3}\right),{ }^{\mathrm{S}_{3}} \mathrm{He}=0.20 \times$ $10^{24}\left(\mathrm{~cm}^{-3}\right)$

\begin{tabular}{|c|c|c|c|c|c|}
\hline $\begin{array}{l}\mathrm{T}_{\mathrm{e}} \\
(\mathrm{keV})\end{array}$ & $\begin{array}{c}\mathrm{t} \\
(\mathrm{s})\end{array}$ & $\begin{array}{c}\mathrm{n}_{\mathrm{D}}(\mathrm{t}) \\
\left(\mathrm{cm}^{-3}\right)\end{array}$ & $\begin{array}{c}\mathrm{n}_{{ }_{H} \mathrm{He}}(\mathrm{t}) \\
\left(\mathrm{cm}^{-3}\right)\end{array}$ & $\begin{array}{c}n_{\alpha}(t) \\
\left(\mathrm{cm}^{-3}\right)\end{array}$ & $\begin{array}{c}\mathrm{E}_{\mathrm{f}}(\mathrm{t}) \\
(\mathrm{keV})\end{array}$ \\
\hline 15 & $10^{-20}$ & $6.2 \mathrm{E} 23$ & $1.9 \mathrm{E} 23$ & $1.6 \mathrm{E} 13$ & 0.014 \\
\hline 15 & $10^{-11}$ & $4.2 \mathrm{E} 21$ & $1.3 \mathrm{E} 21$ & $2.2 \mathrm{E} 19$ & $1.43 \mathrm{E} 6$ \\
\hline 15 & 60 & $1.2 \mathrm{E} 12$ & $3.9 \mathrm{E} 11$ & 0.01 & $6.94 \mathrm{E} 14$ \\
\hline 15 & 100 & $1.2 \mathrm{E} 12$ & $3.9 \mathrm{E} 11$ & 0.01 & $4.28 \mathrm{E} 20$ \\
\hline 50 & $10^{-20}$ & $6.2 \mathrm{E} 23$ & $1.9 \mathrm{E} 23$ & $1.8 \mathrm{E} 15$ & 1089.49 \\
\hline 50 & $10^{-11}$ & $3.1 \mathrm{E} 21$ & $2.7 \mathrm{E} 20$ & $1.0 \mathrm{E} 21$ & $5.94 \mathrm{E} 10$ \\
\hline 50 & 60 & $1.2 \mathrm{E} 12$ & $3.9 \mathrm{E} 11$ & 1.5 & $2.88 \mathrm{E} 19$ \\
\hline 50 & 100 & $1.2 \mathrm{E} 12$ & $3.9 \mathrm{E} 11$ & 1.5 & $1.78 \mathrm{E} 25$ \\
\hline 100 & $10^{-20}$ & $6.2 \mathrm{E} 23$ & $1.9 \mathrm{E} 23$ & $1.0 \mathrm{E} 16$ & 6168.03 \\
\hline 100 & $10^{-11}$ & $2.8 \mathrm{E} 21$ & $6.4 \mathrm{E} 17$ & $1.3 \mathrm{E} 21$ & $1.02 \mathrm{E} 11$ \\
\hline 100 & 60 & $1.2 \mathrm{E} 12$ & $3.9 \mathrm{E} 11$ & 8.5 & $4.96 \mathrm{E} 19$ \\
\hline 100 & 100 & $1.2 \mathrm{E} 12$ & $3.0 \mathrm{E} 11$ & 8.5 & $3.06 \mathrm{E} 25$ \\
\hline 380 & $10^{-20}$ & $6.2 \mathrm{E} 23$ & $1.9 \mathrm{E} 23$ & $3.2 \mathrm{E} 16$ & 18724.7 \\
\hline 380 & $10^{-11}$ & $2.8 \mathrm{E} 21$ & $5.4 \mathrm{E} 11$ & $1.3 \mathrm{E} 21$ & $1.10 \mathrm{E} 11$ \\
\hline 380 & 60 & $1.2 \mathrm{E} 12$ & $3.9 \mathrm{E} 11$ & 26.0 & $5.38 \mathrm{E} 19$ \\
\hline 380 & 100 & $1.2 \mathrm{E} 12$ & $3.9 \mathrm{E} 11$ & 26.0 & $3.32 \mathrm{E} 25$ \\
\hline
\end{tabular}




\section{Conclusion}

The advantages of $\mathrm{D}+{ }^{3} \mathrm{He}$ over $\mathrm{D}+\mathrm{T}$ appear as full-lifetime materials, reduced radiation damage, less activation, absence of tritium breeding blankets, highly efficient direct energy conversion, easier maintenance, proliferation resistance. $\mathrm{D}+{ }^{3} \mathrm{He}$ reaction is very attractive from a theoretical point of view since it does not produced neutrons. A D $+{ }^{3} \mathrm{He}$ fuel fusion reactor would also possess substantial safety and environmental advantages over $\mathrm{D}+\mathrm{T}$. Efficient $\mathrm{D}+{ }^{3} \mathrm{He}$ fusion energy would benefit terrestrial electricity ,space power, and space propulsion. Fusion using $\mathrm{D}+{ }^{3} \mathrm{He}$ fuel requires significant physics development particularly of plasma confinement in high performance alternate fusion concept. Economically accessible ${ }^{3} \mathrm{He}$ on earth exists in sufficient quantities for an engineering. In a $\mathrm{D}+{ }^{3} \mathrm{He}$ fuel mixture $\mathrm{D}+\mathrm{D}$ reaction fusion also is occurred. The main difficulties for $\mathrm{D}+{ }^{3} \mathrm{He}$ reaction are the high temperature conditions and the scarceness of ${ }^{3} \mathrm{He}$ on earth.

\section{References}

[1] J D Lindl Phys Plasmas 23933 (1995) and Phys Plasmas 11 339 (2004).

[2] S E Bodner et al. Phys Plasmas 5, 1901 (1998)

[3] N.G. Basov, S.Y. Guskov and L.P. Feokistov, J. Sov. Laser Res. 13, 396 (1992).

[4] M Tabak et al Phys Plasmas 11626 (1994)

[5] K. A. Tanaka, R. Kodama, H. Fujita, et al., Phys. Plas-mas 7, 2014 (2000).

[6] Xing Z. Li, Qing M. Wei and Bin Liu, Nucl. Fusion 48, 125003 (5pp) (2008).

[7] V. Bychenkov, W. Rozmus, A. Maksimchuk, D. Umstadter, and C.Capjack, Plasma Phys. Rep. 27, 1017 (2001).

[8] H. Schwoerer, S. Pfotenhauer, O. Jackel, K. U. Amthor, Ziegler, R. Sauerbrey, K. W. D. Ledingham, and T. Esirkepov ,Nature London439,445 (2006).

[9] C. Bathke, H. Towner, and G. H. Miley, Trans. Am. Nucl. Soc. 